\title{
AN INTEGRATED PERFORMANCE MANAGEMENT FRAMEWORK FOR A MULTI-BUSINESS COMPANY
}

\author{
H.M. Aburas \\ Department of Industrial Engineering \\ King Abdulaziz University, Saudi Arabia \\ haburas@kau.edu.sa
}

\begin{abstract}
A multi-business company is a complex entity. Evaluating corporate performance of such an organisation is even more challenging. Corporate performance is inherently multidimensional in nature, is viewed from various perspectives, and has to satisfy multiple objectives. It is multi-dimensional in the sense of being a function of many variables that drive firm performance; multi-perspectival, from various stakeholders' standpoints; and multi-objectives are to be optimised. So there is no single corporate performance evaluation tool that can be prescribed as a stand-alone gauge; however, a unified and holistic corporate performance management system can be developed from multiple tools. This paper attempts to bring together a variety of performance management tools that have evolved and developed in theory, and have been tested and applied in practice. In developing this convergence, first a set of criteria that answers the multi-dimensional, multi-perspectival, and multi-objective requirements of a firm's performance will be identified and weighted. Second, management tools that have been used either singly or in combination by multi-business companies are reviewed and ranked against the chosen criteria. Finally, an integrated model or framework that brings together and unifies the elements of these ranked performance management tools is proposed.
\end{abstract}

\section{OPSOMMING}

' $n$ Multi-maatskappy-onderneming is ' $n$ komplekse entiteit. Die evaluasie van maatskappyprestasie van so ' $n$ onderneming is self meer van ' $n$ uitdaging. Maatskappyprestasie is inherent multidimensioneel, word uit verskeie perspektiewe beskou en moet veelvuldige doelwitte bevredig. Geen enkele maatstaf is beskikbaar om hierdie fasette van maatskappyprestasie te evalueer, alhoewel ' $n$ holistiese prestasiebestuurstelsel ontwikkel kan word gebaseer op verskillende maatstawwe. Hierdie artikel bring verskillende metodologieë byeen vir die meting van maatskappyprestasie wat multi-dimensioneel, multiperspektiewelik en multi-doelwit-geöriënteerd is. Sodoende word ' $n$ geïntegreerde raamwerk vir die meting van maatskappyprestasie ontwikkel. 


\section{INTRODUCTION}

This paper proposes an integrated performance management framework for a multibusiness company. At the outset, it is recognised that such an organisation is inherently complex, and thus the process of evaluating its performance is perhaps even more complex. Fioretti and Visser [8] cite literature on organisational theory that suggests that the complexity of an organisation arises from two strands: First, the structural features of the organisation, in terms of the number and the inter-relationships of differentiated sub-units (both vertical and horizontal), with each having its own formal structure, goals, and orientations. This poses a challenge to the integration of the performance of the organisation's subsystems in order to present the organisation's performance as a coordinated whole. Second, organisational complexity arises from the behaviour originating from the interaction between and among the organisation's sub-units. This poses an even greater challenge, as organisational behaviour and its effects are unpredictable.

A multi-business company can take one of several basic organisational forms to suit its requirements - i.e. the organisation's specific performance characteristics or attributes: centralised functional form, decentralised divisional form, adaptive (project management) or matrix form, and innovative form. Variants of these basic forms have evolved over the years, again strengthening the argument about complexity in business organisations. In assessing organisational performance, Ansoff and Brandenburg [1] categorise the performance attributes as follows: steady-state efficiency, operating responsiveness, strategic responsiveness, and structural responsiveness. In their paper they propose an organisational design structure that maximises organisational performance potential to achieve given objectives.

The above briefly describes and establishes the complexity of organisations and their performance from a firm's internal perspective. It is equally important to view the issue from the vantage point of the external environment that impinges on the organisation. This adds to the complexity, and thus a total systems approach is necessary to arrive at a meaningful framework for evaluating an organisation's performance in general, and multibusiness companies in particular.

McKenzie and James [14] argue that a systems approach is concerned with the "relations between the elements which make up the system, not to the elements and how they work, or what they are made of". Peters [17] draws attention to the human factors that underlie organisations: "Quality is practical, and factories and airlines and hospital labs must be practical. But it is also moral and aesthetic. And it is also perceptual and subjective". These highlight the need (1) to consider both the human elements and the moral and social responsibility of organisations, and (2) to adopt a systems approach to develop a performance management framework.

As a final introductory note, Orlitzky, Schmidt and Rynes [16] have done extensive research using a meta-analysis of fifty-two studies, and report a strong positive correlation between Corporate Social Performance (CSP) and Corporate Financial Performance (CFP). This strengthens the proposition that corporate social responsibility is a significant factor to be included in the proposed corporate performance management framework.

This paper will focus on examining the characteristics of a multi-business company that adopts either the centralised functional form or the decentralised divisional form and their variants, and propose an integrated performance management framework that takes into account internal and external system perspectives and relationships, performance attributes and criteria, financial and non-financial results and drivers, the management control system employed, and organisational leadership and culture. 


\section{REVIEW OF CORPORATE PERFORMANCE MANAGEMENT TOOLS}

Several management and management control tools serving different purposes have been developed during the last three decades. These tools were based on methodologies and approaches attendant to the varied needs of actual organisations (both public and private) prevailing at the time. Among the most significant developments in management practice are the emergence of ISO 9000, Total Quality Management (TQM), and the excellence models: Baldrige National Quality Program (BNQP), and the European Foundation for Quality Management (EFQM), the Balanced Scorecard (BSC), Enterprise Risk Management (ERM), and Corporate Performance Management (CPM). It is beyond the scope of this paper to discuss the scope, benefits, and methodologies behind each. However, the literature research covers the results of studies and research on the above management practices in relation to corporate performance.

Benner and Veloso [2] cite literature that shows contrasting results of implementing process management practices such as the TQM, BNQP, and ISO 9000 in relation to a firm's performance, especially with regard to the firm's objective of achieving sustainable competitive advantage. On ISO 9000 in particular, they report that - since this practice is generic and has been readily adopted by thousands of organisations - the financial benefits for early adopters do not happen to late adopters unless they tie these practices up to firmspecific, unique, and inimitable capabilities in creating competitive advantage. They have also established that, while adopting ISO 9000 directly results in improved process efficiencies, it does not directly translate into improved financial performance.

Easton and Jarrel [6] support the above argument with the findings of their research into 108 early adopters of TQM, indicating that performance, measured by both accounting variables and stock returns, improved by using TQM. Hendricks and Singhal [9] conducted a study on 600 quality award winners who provided evidence of good financial results from implementing TQM effectively. Boyne and Walker [3], however, report no conclusive evidence of a positive correlation between a firm's performance and implementation of TQM, based on a meta-analysis of 25 studies conducted to establish a correlation between TQM and performance.

Hendricks and Singhal [10] reported the results of research conducted over two five-year periods: the winners of business excellence quality awards (Baldrige and UK Business Excellence) outperformed the benchmarks on almost every performance measure: share price, operating income, growth in sales, total assets, productivity, and efficiency.

Kaplan and Norton [11] introduced and popularised the BSC as a management tool. They presented it as an integrative device that looks at both the financial and non-financial outcomes and activities of an organisation. Brudan [5] reports that over a period of ten years since its introduction, BSC has evolved from a performance measurement tool (1992), to a performance management system (1996), and a strategic management and control system (2000). From then on, owing to wide acceptance and implementation, the BSC has continued to evolve, being used for strategic alignment, strategy communications, and even facilitating strategy development. Lawrie and Cobbold [13] likewise affirm its evolution into an effective strategic performance management tool. There are attempts to use it as an integrating framework to gauge corporate performance in conjunction with other performance management tools and practices (Lawrie [12]).

Another management tool that rose to prominence is the concept known as Enterprise Risk Management. ERM deals with risks and opportunities affecting value creation or preservation, and the Committee of Sponsoring Organisations of the Treadway Commission (COSO) defines it as follows:

"Enterprise risk management is a process, effected by an entity's board of directors, management and other personnel, applied in strategy setting and across the enterprise, designed to identify potential events that may affect the entity, and manage risk within 
its risk appetite, to provide reasonable assurance regarding the achievement of entity objectives."

The framework identifies the following four entity objective categories:

1. Strategic: high level goals, aligned with and supporting its mission;

2. Operations: effective and efficient use of resources;

3. Reporting: reliability of reporting; and

4. Compliance: compliance with applicable laws and regulations.

Furthermore, ERM propounds eight inter-related components: internal environment, objective setting, event identification, risk assessment, risk response, control activities, information and communication, and monitoring. These components may traverse the whole enterprise, from entity level down to subsidiary level.

Mihok [15] proposes a system of Corporate Performance Management (CPM) as a new way of directing companies. He views CPM as integrating the methodologies of BSC, Economic Value Added (EVA), Activity Based Management, and ISO 9000 under one umbrella. It is noted, however, that the proposal stems from a software development point of view rather than a business point of view. However, BSC institutions such as the Balanced Scorecard Collaborative, the Balanced Scorecard Institute, and 2GC Active Management have attempted to build and develop CPM using the balanced scorecard methodology as a framework. Likewise, giant software companies like SAP-Oracle, IBM Cognos, SAS, CorVu, Hyperion, and a few others offer CPM in their suite of business intelligence and/or enterprise management products.

The above review indicates that no single management tool is adequate to evaluate corporate performance as a whole. A simple combination of these tools is not integration, as each will be implemented independently of the others without establishing the required convergence of these tools.

\section{PROPOSED FRAMEWORK}

\subsection{Corporate performance criteria}

Corporate performance is inherently multi-dimensional in nature, is viewed from various perspectives, and must satisfy multiple objectives. It is multi-dimensional in the sense of being a function of many variables that drive a firm's performance: environment, processes, people, and control systems; multi-perspectival as viewed from various stakeholders' standpoints, financial and social; and set against a multiplicity of objectives that need to be optimised: quality, excellence, continuous improvement, and sustainability.

In other words, it is important that one views corporate performance from the vantage point both of results or outcomes, and of the activities or drivers that produce those results. For both, it is equally important to define the underlying objectives and their corresponding targets or levels of acceptable, if not excellent, performance. Thus the design of corporate performance criteria will revolve around these three key elements: outcomes, activities, and objectives.

In developing the performance criteria, the criteria cited by Ansoff and Brandenberg [1] in proposing a language or process for organisational design will be built upon. They have cited six, and in the context of this paper these are enumerated in order of performance design importance, as follows: (a) structural responsiveness criteria; (b) strategic responsiveness criteria; (c) operational responsiveness criteria; (d) decision and information quality criteria; (e) economic and human resource feasibility criteria; and (f) steady-state efficiency criteria. 'Structural responsiveness criteria' will refer here to leadership capability and specialised organisational resources to effect structural change. This will also 
cover corporate governance for transparency, compliance, and performance improvement. 'Strategic responsiveness criteria' will refer to the strategic planning processes and management controls employed to achieve good strategic performance. 'Operational responsiveness criteria' will refer to the operations planning, control, and budgeting processes employed to achieve good operational and tactical performance. 'Decision and information quality criteria' will refer to the decision support systems, quality management systems, and information management systems employed to achieve good overall performance. 'Economic and human resource feasibility criteria' will refer to the organisational culture and incentives and rewards system employed to retain and motivate employees to achieve high levels of performance. Finally, 'steady-state efficiency criteria' will refer to the processes (strategic, operational, and tactical) and control systems employed to sustain good corporate performance.

The importance of how a multi-business company fares in carrying out its corporate social and environmental responsibility cannot be underestimated. Clarkson [5] presents the findings of a 10-year research programme, and cites literature on the necessity of assessing how corporations manage relationships with various stakeholder groups. Feldman, Soyka and Ameer [7] report that sound environmental management leads to reduced risk for the firm, which in turn is valued by financial markets and ultimately translates into increased market valuation of the firm. Thus it is logical to add to the set mentioned above 'corporate responsibility responsiveness criteria', which will cover how effectively and efficiently the organisation fulfils its obligations to the community at large.

In summary, the author proposes seven criteria built into an integrated corporate performance management framework:

1. Structural responsiveness: leadership, corporate governance, special organisational resources

2. Strategic responsiveness: strategic planning, management control system

3. Operational responsiveness: operations planning and control, budgeting

4. Decision and information quality: decision support systems, quality management systems, information management

5. Economic and human resource feasibility: people, organisation, culture, rewards system

6. Steady-state efficiency: processes and control systems

7. Corporate responsibility responsiveness: corporate social and environmental responsibility

Each of the above criteria follows the rigorous definition of outcome and activity performance indicators, as well as the corresponding outcome and activity objectives. At the same time the relative numerical weighting factor for each criterion will have to be defined. For a multi-business organisation, the process requires tacit knowledge of its own organisational structure, its strategic position, its core competencies, its resources, and its business objectives. For example, the organisational form taken by a multi-business firm inherently dictates how well or poorly it fares against each of these criteria. In other words, a multi-business entity cannot perform strongly against all seven criteria unless it evolves itself an organisational form that is relevant and responsive to its needs and its capability.

Thus a contextual approach to defining the outcome and activity indicators, together with their corresponding objectives, and the definition of relative numerical weighting factors for each of the criteria, has to be adopted. For the purpose of developing the performance management framework, each criterion $C_{i}$ will be given a relative weighting factor $w_{i}$, for $i$ $=1$ to 7 . The weighting factor quantifies the relative importance of each criterion in realtion to the others, but is set against the form of organisation one is considering.

For each of the criteria, outcome and activity indicators and their associated goals or objectives are defined. Thus, if we represent each outcome as $O_{m}$ and each activity as $A_{n}$, 
there are $G_{k}$ performance goals or objectives (where $k=1$ to $m+n$ ) to be considered for each criterion of the proposed performance management framework.

\subsection{Ranking management tools against performance criteria}

For modelling purposes, each available management tool is denoted by $M_{j}$. Each management tool is given a rating index to indicate its usefulness in enhancing, measuring, monitoring, controlling, and predicting corporate performance for each criterion. The suggested rating index is as follows: High $(H)$, Moderate $(M)$, Low $(L)$, and Not Applicable $(X)$, indicating the degree of utility of each tool against each criterion. For purposes of quantification, $\mathrm{H}=3, \mathrm{M}=2, \mathrm{~L}=1$, and $\mathrm{X}=0$.

Mapping the management tools $M_{j}$ against the previously described performance criteria $C_{i}$ and performance objectives $G_{i k}$ produces a three-dimensional framework, shown in Figure 1 below.

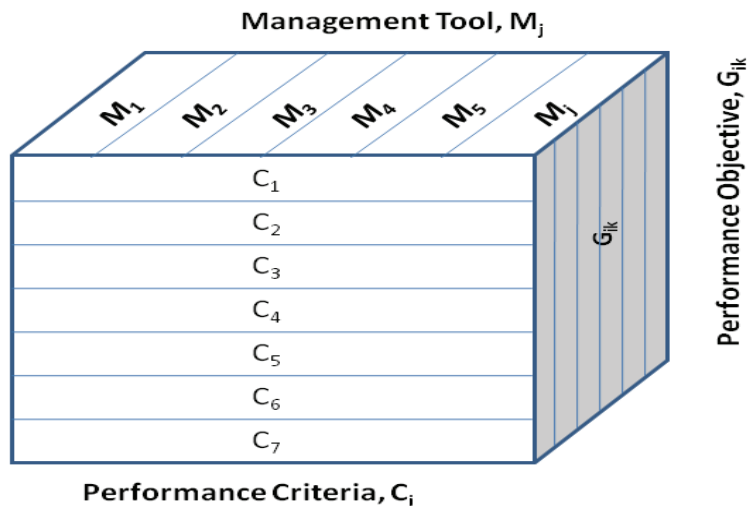

Figure 1: A performance management framework

To implement the proposed management framework, the following algorithm is prescribed:

1. For each performance criterion $C_{i}$, assign relative weighting factors $\mathbf{W}_{\mathbf{i}}$.

2. Define all performance objectives $G_{i k}$ derived from outcome $\mathbf{O}_{m}$ and activity $A_{n}$ variables for each performance criterion $C_{i}$. Thus, the value of $k$ ranges from 1 to $m+n$ for each performance criterion $\mathbf{C}_{\mathbf{i}}$. Do for all $\mathbf{i}$.

3. Distribute the $\mathbf{w}_{\mathbf{i}}$ across all $\mathbf{G}_{\mathbf{i k}}$ in each $\mathbf{i}$ according to an appropriate decision rule. This index, denoted by $x_{i k}$, represents the relative contribution of each performance objective $G_{i k}$ to each performance criterion $C_{i}$. The sum of all $x_{i k}$ should equal $w_{i}$.

4. Rate each management tool $M_{j}$ using the suggested rating index $(H=3, M=2, L=1, X=0)$ against the performance objectives $G_{i k}$. Do for all $\mathbf{k}$. This rating index is denoted as $r_{i j k}$.

5. Repeat step (4) for all j.

6. Repeat steps (4) and (5) for all i.

7. Derive the management tool rating $R_{i j k}$ as the product of $x_{i k}$ and $r_{i j k}$. Do for all $i, j, k$.

8. Summate the $\mathbf{R}_{\mathrm{ijk}}$ for each $\mathbf{i}$. This is denoted as $\mathbf{W}_{\mathrm{ij}}$ and represents the aggregate utility index of a management tool $M_{j}$ on each performance criterion $C_{i}$.

9. Get the sum of all $\mathbf{W}_{\mathbf{i j}}$ across all $\mathbf{i}$. This is denoted as $\mathbf{X}_{\mathbf{j}}$ and represents the overall value contribution and importance rating of each management tool $M_{j}$.

10. Ordinally rank all management tools $M_{j}$ according to the derived $X_{j}$. This indicates the priority of the management tools to be adopted within the organisation. 


\subsection{Implementation strategy}

The initiative to implement the set of interdependent performance evaluation tools defined above will have to be branded as the Integrated Corporate Performance Management (ICPM) initiative. This should represent a convergence of these tools, spelling out the overall roadmap or implementation strategy. For implementation, however, it will be helpful to break the 'elephant' into critical and manageable components. The following steps (high level) are proposed as the overall implementation strategy or approach:

1. For each of the five performance management tools selected above, identify critical key elements that are either already in place (even if fragmented or ad hoc) or, if nonexistent, are easy to implement. The idea behind this is to identify 'quick-wins'.

2. Develop a unifying philosophy or rationale for ICPM. This will put the initiative in context and provide the platform for successful implementation. At the same time, prepare an overall project implementation plan.

3. Focusing on the critical few that count, develop an ICPM pilot model that can be fasttracked for implementation.

4. Gain top management's understanding, commitment, support, and sponsorship of the overall ICPM project.

5. Implement the ICPM pilot model.

6. Communicate the results of the pilot model to top management.

7. Communicate the 'bigger picture' project implementation plan for kick-off.

8. Identify and organiza enablers (people and systems) for success.

9. Identify and assign project component advocates who will own and manage components of the project.

10. Establish a project management office to monitor and manage the project.

It should be noted that, for the ICPM and each of its five components, it is absolutely necessary that top management's commitment is established to organiza, govern, and sustain the benefits that the system aims to bring to the organization.

\section{APPLICATION OF THE PERFORMANCE MANAGEMENT FRAMEWORK - AN ILLUSTRATIVE EXAMPLE}

Table 1 is an illustrative example of weighting factors that could be assigned to each of the criteria for a decentralised divisional multi-business organisation. The weighting factors are subjectively assigned by selected people within the organisation, who have to reach a consensus on the relative importance of the defined criteria. In this example, the relative weights add up to 100, but it is not a requirement to work through the prescribed algorithm. What is necessary is that the assigned numbers reflect the relative importance of each criterion to the overall performance of the firm.

For purposes of illustrating the use of the proposed performance management framework, five prominent management practices or tools have been selected: BSC, ISO 9000/TQM, the BNQP/EFQM excellence models, ERM, and CPM. The selection is based on the prevalence of these tools in practice and the perceived strategic and operational value they offer organisations. 


\begin{tabular}{|l|l|l|}
\hline No & \multicolumn{1}{|c|}{ Criteria, Ci } & $\begin{array}{l}\text { Weighting } \\
\text { Factor, wi }\end{array}$ \\
\hline 1 & $\begin{array}{l}\text { Structural responsiveness: leadership, corporate governance, special } \\
\text { organisational resources }\end{array}$ & 16 \\
\hline 2 & Strategic responsiveness: strategic planning, management control system & 16 \\
\hline 3 & Operational responsiveness: operations planning and control, budgeting & 14 \\
\hline 4 & $\begin{array}{l}\text { Decision and information quality: decision support systems, quality } \\
\text { management systems, information management }\end{array}$ & 13 \\
\hline 5 & $\begin{array}{l}\text { Economic and human resource feasibility: people, organisation, culture, } \\
\text { rewards system }\end{array}$ & 14 \\
\hline 6 & $\begin{array}{l}\text { Steady-state efficiency: processes and control systems } \\
\text { Corporate responsibility responsiveness: corporate social and environmental } \\
7\end{array}$ & 13 \\
\hline
\end{tabular}

\section{Table 1. Performance criteria weighting factors}

Furthermore, to test the validity of the model, the conglomerate structure of an existing organisation in Saudi Arabia has been used to define the performance objectives (strategic and operational). Again, the ratings assigned each management tool and mapped against a performance objective are done subjectively, but are based on the consensus of evaluators comprising top and middle layers of management who debated and finally agreed on the most appropriate rating to be assigned. This process results in a collegial approach in decision-making about the selection and prioritisation of the implementation of the relevant management tools for strategic, tactical, and operational purposes. In the example used, the resulting ranking of the selected management tools is as follows: CPM (first), BSC (second), BNQP/EFQM (third), ERM (fourth), and ISO 9000/TQM (fifth and last).

It should be noted that, for the same set of management tools used in another context i.e. another organisational form, as cited by Ansoff and Brandenburg [1] - the ranking is expected to change. The ranking is also likely to change even with the same organisational form of different companies within the same industry, as they will necessarily have different performance objectives and thus will be given different weighting factor assignments.

\section{CONCLUSION}

The notion of firm performance is complex. It is inherently multi-dimensional in many aspects: inputs, processes, outputs, and perspectives. As such, formulating and adopting a single approach, methodology, tool, or system is close to impossible. From a pragmatic and practical standpoint, the best is to formulate a framework that addresses the key success factors of a firm and attempts a convergence of performance evaluation tools that are relevant to these factors. The author has followed this path, and has presented a framework that prioritised a set of relevant corporate performance management tools, based on a predefined set of performance criteria.

The objective is to formulate a framework that will assist management of a multi-business company in its journey towards excellence, building quality into its mission-critical activities, and equipping its management systems with practical and relevant tools to gauge performance.

Again, it should be stressed that whatever methodology, tool, or technique is adopted by the firm, a necessary and sufficient condition for excellent or superior performance is leadership by top management. When senior leaders, guided by core values, create, shape, and change the mindsets that ultimately underpin high performance, they help the organisation to establish the practices that lead to superior results. 
In developing the above integrated performance management framework, it should be noted that a systemic and holistic approach may require establishing the inherent cause and effect relationship among the performance criteria. This may be necessary in theory, but the objective here is to present a simple, practical, and pragmatic framework that addresses the complex task of evaluating a firm's performance. Be that as it may, capturing the cause and effect relationships among the seven criteria, and establishing correlations between activity and outcome variables, are potentially good areas for further research and model enhancement.

\section{REFERENCES}

[1] Ansoff, H. \& Brandenburg, R. 1971. A language for organizational design: Part II. Management Science, Application series, 17(12), pp 717-731.

[2] Benner, M. \& Veloso, F. 2008. ISO 9000 practices and financial performance: A technology coherence perspective. Journal of Operations Management, 26(5), pp 611-629.

[3] Boyne, G. \& Walker, R. 2002. Total quality management and performance. Public Performance and Management Review, 26(2), pp 111-131.

[4] Brudan, A. 2005. Balanced scorecard typology and organizational impact. actKM Online Journal of Knowledge Management, 2(1), pp 1-14.

[5] Clarkson, M. 1995. A stakeholder framework for analyzing and evaluating corporate social performance. Academy of Management Review, 20(1), pp 92-117.

[6] Easton, G. \& Jarrell, S. 1998. The effects of total quality management on corporate performance: An empirical investigation. Journal of Business, 71(2), pp 253-307.

[7] Feldman, S., Soyka, P. \& Ameer, P. 1996. Does improving a firm's environmental management system and environmental performance result in a higher stock price? ICF Kaiser Intl, USA.

[8] Fioretti, G. \& Visser, B. 2004. A cognitive interpretation of organizational complexity. E:CO, 6(1-2), pp 11-23.

[9] Hendricks, K. \& Singhal, V. 2000. The impact of Total Quality Management (TQM) on financial performance: Evidence from quality award winners. Strategos Inc, USA.

[10] Hendricks, K. \& Singhal, V. 2003. The impact of business excellence on financial performance. British Quality Foundation, United Kingdom.

[11] Kaplan, R. \& Norton, D. 2006. Alignment. Harvard Business School Press, Boston, USA.

[12] Lawrie, G. 2001. Combining EVA with balanced scorecard to improve strategic alignment. Berkshire, United Kingdom: 2GC.

[13] Lawrie, G. \& Cobbold, I. 2004. Development of the $3^{\text {rd }}$ generation balanced scorecard. Berkshire, United Kingdom: 2GC.

[14] McKenzie, C. \& James, K. 2004. Aesthetics as an aid to understanding complex systems and decision judgment in operating complex systems. E:CO, 6(1-2), pp 3239.

[15] Mihok, J. 2006. Corporate performance management as a new way in directing companies. Acta Montanistica Slovaca, 11(4), pp 278-282.

[16] Orlitzky, M., Schmidt, F. and Rynes, S. 2003. Corporate social and financial performance: A meta-analysis. Organization Studies, 24(3), pp 403-441.

[17] Peters, T. 1989. Thriving on chaos. Pan Books, London, United Kingdom. 
http://sajie.journals.ac.za 